This is peer-reviewed accepted manuscript of:

Terziroli Beretta-Piccoli B, Ripellino P, Gobbi C, Cerny A, Baserga A, Di Bartolomeo C, Bihl F, Deleonardi G, Melidona L, Grondona AG, Mieli-Vergani G, Vergani D, Muratori L; Swiss Autoimmune Hepatitis Cohort Study Group. Autoimmune liver disease serology in acute hepatitis E virus infection.

J Autoimmun. 2018 Nov;94:1-6.

The final published version is available online at: https://10.1016/i.jaut.2018.07.006

Rights / License:

The terms and conditions for the reuse of this version of the manuscript are specified in the publishing policy. For all terms of use and more information see the publisher's website.

This item was downloaded from IRIS Università di Bologna (https://cris.unibo.it/)

When citing, please refer to the published version. 


\section{Autoimmune liver disease serology in acute hepatitis E virus infection}

${ }^{1}$ Benedetta Terziroli Beretta-Piccoli, ${ }^{2}$ Paolo Ripellino, ${ }^{2}$ Claudio Gobbi, ${ }^{1}$ Andreas Cerny, ${ }^{1}$ Adriana Baserga, ${ }^{1}$ Claudia Di Bartolomeo, ${ }^{3}$ Florian Bihl, ${ }^{4}$ Gaia Deleonardi, ${ }^{4}$ Laura Melidona, ${ }^{4}$ Ana Gabriela Grondona, ${ }^{5}$ Giorgina Mieli-Vergani, ${ }^{6}$ Diego Vergani, ${ }^{7}$ Luigi Muratori, and the *Swiss Autoimmune Hepatitis Cohort Study Group.

1 Fondazione Epatocentro Ticino, Lugano, Switzerland;

2 Neurocentro della Svizzera Italiana, Ospedale regionale di Lugano, Lugano, Switzerland; 3 Servizio di Epatologia EOC, Bellinzona, Switzerland;

4 LUM Autoimmunity and Allergy AUSL Bologna, Italy;

5 Paediatric Liver, GI and Nutrition Centre, MowatLabs, King's College Hospital, London, UK;

6 Institute of Liver Studies, MowatLabs, King's College Hospital, London, UK;

7 DIMEC, University of Bologna, Bologna, Italy.

\section{Abstract}

The etiology of autoimmune hepatitis $(\mathrm{AIH})$ is unknown, though hepatotropic viruses may be potential triggers. Hepatitis E virus (HEV) infection, an increasingly recognized cause of acute hepatitis, has been misdiagnosed as $\mathrm{AlH}$ due to the occurrence of autoantibodies during its acute phase. It has also been suggested that HEV infection may lead to or unmask AlH. The prevalence of positive HEV serology has been ascertained in patients with $\mathrm{AlH}$, but the prevalence of $\mathrm{AlH}$-related autoantibodies in patients with HEV infection has not been systematically tested. We aimed to investigate whether acute HEV infection is associated with the presence of AlH-relevant autoantibodies, following the liver autoimmune serology guidelines of the International AlH Group. We tested 48 patients with acute HEV infection. Half of them had at least one autoantibody, $17 \%$ two autoantibodies. Anti-nuclear antibody (ANA) were detected in 16 (33\%), anti-smooth muscle antibody (SMA) in 10 (21\%), and anti-neutrophil cytoplasmic antibody (ANCA) in 
$7(14.6 \%)$. Of note, two patients showed SMA with VG or VGT patterns and five had ANA with homogeneous appearance, both being typical of AlH type 1. Other AlH-specific autoantibodies were negative. Atypical anti-mitochondrial antibody, without evidence of primary biliary cholangitis, was positive in one patient, disappearing at follow-up. Followup (median 12 months) serum was available from seven autoantibody positive patients: two became negative, while five remained positive, although no patient developed $\mathrm{AlH}$ to date. In conclusion, autoantibodies are frequently present during acute HEV infection, indicating that HEV should always be excluded before diagnosing $\mathrm{AlH}$. Importantly, a minority of patients with acute hepatitis E develops AlH-specific autoantibodies, and, though they did not progress to autoimmune liver disease in the short-term, they warrant long-term monitoring.

\section{Keywords}

acute hepatitis E - autoimmune hepatitis - autoimmune liver serology - autoimmune hepatitis-specific autoantibodies

\section{Highlights}

- Non-specific liver autoantibodies are frequently positive in acute HEV infection

- Specific liver autoantibodies are occasionally detected in acute HEV infection

- Acute HEV should always be ruled out before diagnosing and treating autoimmune hepatitis

- HEV patients with autoimmune hepatitis-specific positive serology should be followed up long term

\section{Introduction}

Hepatitis $E(H E V)$ is an emerging cause of acute hepatitis in industrialized countries, where it is a food-borne zoonotic infection, transmitted mainly by uncooked or undercooked pork meat [1]. It is usually an acute self-limiting disease, but it can cause chronic infection with rapid progression to liver cirrhosis in organ transplant recipients, patients with hematological malignancies requiring chemotherapy, and individuals with HIV infection [1-3]. In Europe, the seroprevalence of HEV has been assessed in different countries, ranging from $0.6 \%$ and $52.5 \%$ [4]; in Switzerland a small study reported a seroprevalence of $4.9 \%$ [5], but a more recent and larger study analyzing 550 blood 
donors reported a seroprevalence ranging from $4.2 \%$ to $21.8 \%$ [6]. The high variability of these results is due to the use of different techniques, since the sensitivity and specificity of the first-generation assays have been unsatisfactory $[4,6]$.

Autoimmune hepatitis $(\mathrm{AlH})$ is a rare, chronic inflammatory liver disease characterized by high transaminase and IgG levels, female preponderance, positive autoantibodies, histologically by interface hepatitis, and a swift response to steroid-based treatment [7]. Its etiology is still unknown. The disease is probably initiated by an autoantigen (as yet unidentified) presented to naive CD4+ T-helper (Th0) cells in the liver, in a genetically predisposed subject [7]. Viruses have been recognized as possible AlH triggers, mainly through a mechanism of molecular mimicry, a process that redirects immune responses to external pathogens to structurally similar self-components [8]. This concept is best documented in AlH type 2, where aminoacidic sequences of the hepatitis $\mathrm{C}(\mathrm{HCV})$ virus are shared in common with the auto-antigenic target, cytochrome P4502D6 (CYP2D6), of the anti-liver kidney microsomal 1 (LKM1) antibody, the disease hallmark [9]. Up to 10\% of HCV infected subjects are seropositive for anti-LKM1 [10,11], and type $2 \mathrm{AlH}$ following HCV infection has been reported [12].

In one large German study the seroprevalence of HEV has been reported to be higher in patients with $\mathrm{AlH}(7.7 \%)$ than in blood donors $(2 \%)$, patients with rheumatoid arthritis (3.5\%) or chronic hepatitis B and C infection (2.8\%) [13]. The same group reported in a later study a higher HEV seroprevalence already at the time of AlH diagnosis [14]. However, these results could not be reproduced in a cohort of AlH patients from the Netherlands [15], where the incidence of HEV is particularly high [16]. HEV IgG seroprevalence in both AlH and blood donors was around 27\% [15]. Single cases of acute HEV infection with positive liver autoantibodies have been reported [17-21]. Taken together, these data raise the question whether HEV can trigger $\mathrm{AlH}$.

Autoantibodies are key to the diagnosis of AlH: presence of anti-LKM1 and/or anti-liver cytosol 1 (anti-LC1) antibodies define type $2 \mathrm{AlH}$, and $>95 \%$ of type $1 \mathrm{AlH}$ patients are seropositive for anti-nuclear (ANA) and/or anti-smooth muscle antibodies (SMA) [22]. While the prevalence of positive HEV serology has been investigated in patients with $\mathrm{AlH}$, no study to date has assessed the prevalence of AlH-related autoantibodies in patients with HEV infection. Thus, we aimed to investigate whether acute HEV infection is associated with the presence of $\mathrm{AlH}$-relevant autoantibodies.

\section{Material and Methods}


The project was approved by the Scientific Committee of the Swiss AlH cohort study. The study protocol conforms to the ethical guidelines of the 1975 Declaration of Helsinki and was approved by the local Ethics Committee. Written informed consent was obtained from each patient at study enrolment.

Sera from 50 adult patients ( $>16$ years of age) with acute HEV infection diagnosed in the Ticino Canton between May 2015 and May 2017 were available for testing. Clinical information included: age, gender, pre-existing HCV, HBV or HIV infection, history of autoimmune diseases, concomitant type II diabetes mellitus, presence of cirrhosis, immunosuppression, current malignancies, alcohol and drug abuse, and extra-European travel in the last six months. Pre-existing AlH and chronic viremic HCV, HBV or HIV infections were exclusion criteria. Acute HEV infection was defined as positive HEV RNA in serum/plasma or feces, and/or combined positive serum anti-HEV IgG and IgM. HEV viral load was tested by Fast Track Diagnostic HEV; HEV serology was tested by ELISA Dia.Pro HEV IgG and Dia.Pro HEV IgM, respectively. All sera were collected before any treatment was began. The earliest available transaminase levels at presentation of HEV infection are reported, with an upper limit of normal of $35 \mathrm{IU} / \mathrm{l}$.

Autoimmune liver serology was analysed by indirect immunofluorescence (IIF) on rat kidney, liver and stomach tissue (Euroimmun) for detection of the following autoantibodies: antiSMA, anti-LKM1, anti-LC1, and anti-mitochondrial antibodies (AMA). IIF on HEp2 cells (Euroimmun) was used for ANA detection and pattern definition. All sera were analysed by immunoblot (Euroline Liver-Profile 2 IgG Euroimmun) for anti-soluble liver antigen (SLA), anti-LC1, anti-LKM1, anti-M2 (74 kDa E2 subunit of pyruvate dehydrogenase), anti-M2-3E (fusion protein from the immunogenic domains of E2 subunits of the three enzyme complexes representing the main autoantigens of the M2-antigen). Anti-neutrophil cytoplasmic antibody (ANCA) was tested by IIF on human granulocytes (Euroimmun) and any reactivity was further analysed by ANCA Profile ELISA IgG Euroimmun (proteinase 3, lactoferrin, myeloperoxidase, elastase, cathepsin $\mathrm{G}$, bactericidal/permeability increasing protein). Sera from five well characterized AlH patients from the Swiss AlH cohort (NCT03146884) were used as autoantibody pattern controls. According to the consensus statement by the International AIH Group (IAIHG) [23], cut-off for autoantibody positivity in adults was established at 1:40, except for ANA, where the threshold for positivity on HEp2 cells was established at 1:80. Patients with any positivity were invited to return for a followup serum collection between 10 and 15 months after acute HEV infection. 


\section{Statistics}

Statistical analysis was performed with IBM-SPSS 23 for Windows. Chi-square or Fisher tests were used for assessing the association between presence of autoantibodies and age, gender, concomitant diabetes, cirrhosis, immunosuppression and extra-hepatic complications. The level of significance was set as $\alpha=0.05$ two-tailed.

\section{Results}

Fifty adult patients with acute HEV infection were enrolled; two patients were excluded because of concomitant chronic $\mathrm{HCV}$ infection and pre-existing $\mathrm{AlH}$, respectively. The remaining 48 patients met inclusion criteria; $67 \%$ were men, median age at HEV infection was 53.5 years (range, 17-83) (Table 1). All patients had positive IgM for HEV; HEV RNA was also positive in the serum or feces of 17 patients out of 40 tested. One female patient was diagnosed with coeliac disease at the same time as she presented with acute HEV infection (Table 1, patient 25). None of the patients had a history of recent extra-European travel. Five patients were taking immunosuppressive drugs at the time of HEV diagnosis, two because of kidney transplantation (patient 11: cyclosporin $50 \mathrm{mg} / \mathrm{d}$ and mycophenolate sodium $720 \mathrm{mg} / \mathrm{d}$, reduced after HEV diagnosis; patient 23: azathioprine $75 \mathrm{mg} / \mathrm{d}$ and tacrolimus $4 \mathrm{mg} / \mathrm{d}$ ) and one each because of sarcoidosis (patient 9: prednisone $20 \mathrm{mg} / \mathrm{d}$ ), giant cell arteritis (patient 20: tocilizumab $8 \mathrm{mg} / \mathrm{kg}$ body weight per month), and primary hypereosinophilic syndrome (patient 44: prednisone $5 \mathrm{mg} /$ day and methotrexate 7.5 $\mathrm{mg} /$ week); one further patient had chronic lymphocytic leukemia, but was on no treatment (Table 1). Nine patients had past or current autoimmune diseases (Table 1): two type I diabetes, and one each chronic inflammatory demyelinating polyneuropathy, systemic sarcoidosis, Hashimoto thyroiditis, giant cell arteritis, newly diagnosed coeliac disease, microscopic colitis, myasthenia gravis.

Positive liver autoimmune serology was present in $54 \%$ of the patients, eight $(17 \%)$ having two autoantibodies (Table 1).

ANA was positive in one third of patients, with titers ranging from 1:80 to 1:640 (5 speckled, 2 homogeneous, 2 nucleolar, 7 mixed pattern).

SMA were detected in 10 patients (20.8\%), with titers ranging from 1:40 to 1:320.

ANCA were positive in 7 patients (14.6\%), of whom three had cytoplasmic ANCA (CANCA), three peripheral anti-nuclear neutrophil antibodies (pANNA) and one had perinuclear ANCA (pANCA). Sera positive for ANCA at IIF on human granulocytes did not react with any of the main molecular ANCA targets as assessed by ELISAs. 
AMA, the serological hallmark of primary biliary cholangitis (PBC), was not detected: however, one patient (Table 1, patient 31) showed an atypical AMA IIF pattern on triple rodent tissue (staining all renal tubules, gastric parietal cells and hepatocyte cytoplasm), but AMA was negative when tested against its immunochemically defined target antigens (Euroline Liver-Profile $2 \mathrm{lgG}$ Euroimmun, as described above). The same patient was ANApositive, with a speckled IIF pattern on HEp2 cells.

Anti-SLA, anti-LKM1 and anti-LC1 were negative in all patients.

Transaminase levels at the time of HEV diagnosis were available for 47 patients, and were elevated in $36(75 \%)$.

SMA positivity was associated with ALT $<500 \mathrm{U} / \mathrm{l}(\mathrm{p}=0.02)$ and there was a trend toward an association of SMA positivity with female gender $(p=0.064)$, while ANA and ANCA positivity was not associated with ALT levels or gender. There was no statistically significant association of autoantibody positivity with age, presence of diabetes, cirrhosis, immunosuppression or extra-hepatic HEV complications. ANA positivity showed a trend toward association with the presence of concomitant autoimmune diseases (OR 4.4, Cl 95\%: 0.9-21.6).

At IIF on rat kidney tissue 2/10 SMA positive patients had the VG or VGT pattern, typical of AlH. The patient with the VG pattern (patient 29, Table 1) was a 77-year-old female with hypertension and hyperlipidemia, and a history of microscopic colitis treated by budesonide several years before HEV infection. She had mild, asymptomatic acute HEV infection, with rapid normalization of the transaminase levels, and absence of extrahepatic manifestations. The patient with the VGT pattern (patient 25) also had mild acute hepatitis; however, she was symptomatic because of neurological complications (neuralgic amyotrophy), and the diagnostic work-up for her elevated transaminase levels led to the diagnosis of celiac disease (positive anti-transglutaminase antibodies, duodenal biopsy showing Marsh 3B-3C [24]), which had been asymptomatic. In addition, one year after acute HEV infection she developed erythema nodosum and stage I pulmonary sarcoidosis. Her transaminase levels were normal three months after acute HEV infection. The patient with atypical AMA (patient 31, Table 1), who was also positive for ANA with speckled IIF pattern, had no evidence of PBC (no symptoms, normal liver biochemical tests, normal upper abdomen ultrasound, normal liver stiffness measured by transient elastography). Overall there was no difference in prevalence and type of autoantibodies between the immunosuppressed and the remaining patients. 
Follow-up serum from seven of the 26 patients who had positive autoimmune serology at the time of acute HEV infection, was available (Table 1) between 10 and 15 months later (median 12 months). Two patients were autoantibody negative at follow-up, three were still positive but at lower titers, and two had unchanged autoantibody specificities and titers. The patient with atypical AMA (patient 31) became negative for both AMA and ANA 10 months after acute HEV infection. The SMA-positive patient showing the VGT pattern (patient 25) was still SMA-positive one year later, but with the non AlH-specific V pattern, and had normal transaminase levels. She started a gluten-free diet three months after acute HEV infection. Follow-up serum from the SMA positive patient with the VG pattern (patient 29) was not available.

None of the seven patients followed up for 15 months developed new serological positivities. Transaminase levels were normal at follow-up in all nine patients with available results (Table 1). All patients were followed-up in primary care, none was sent back to the hepatologist for persistent liver disease (median follow up: 20 months) except for patient 23, a kidney transplant recipient positive for both ANA and SMA, who developed chronic HEV infection (defined as persistent positive viremia after 6 months), and was treated with lowdose ribavirin, leading to clearance of the infection one year later, when transaminase levels had normalized.

\section{Discussion}

We have tested systematically, following IAIHG guidelines [23], the whole panel of autoantibodies relevant to the diagnosis of autoimmune liver disease in a large cohort of patients with acute HEV infection. Just over $50 \%$ of our patients had positive autoantibodies, five having the ANA homogeneous pattern usually seen in $\mathrm{AlH}$, and two the SMA pattern (VGT and VG) characteristic of AlH type 1. No patient had autoantibodies diagnostic for AlH type 2 (anti-LKM1 and anti-LC1) and no patient was positive for the AlH-specific anti-SLA.

Autoantibody positivity, in particular in respect to SMA, is not unusual during the course of viral hepatitis, having been reported for hepatitis A, B, C and E [19, 25-29]. Usually, in the course of viral hepatitis SMA displays the non-specific $V$ pattern [23], as detected in most of our HEV patients, and its presence is considered non-specific, though autoantibody positivity has been associated with more severe disease in chronic hepatitis $C$ [30]. Evolution from HAV, HCV and HEV infection to overt AlH has been anecdotally described $[12,21,28,31,32]$, raising the question as to whether these viruses could be involved in the development of $\mathrm{AlH}$ and whether detection of autoantibodies typical of $\mathrm{AlH}$ during acute 
viral infection may herald progression to autoimmune liver disease. Such an evolution has been documented for AlH type 2 in an instructive case report, where primary and secondary anti-LKM1 immune response after acute HCV infection prefigured the onset of overt AlH nine years later [12]. A multiple hit hypothesis was suggested in that case, as the patient had been exposed over the years to a number of viruses (herpes simplex, HCV, cytomegalovirus and Epstein Barr virus) that share amino acid sequences in common with the target of anti-LKM1 antibody, cytochrome P4502D6, resulting in the expansion of self cross-reactive lymphocyte populations through a mechanism of molecular mimicry until the occurrence of overt disease.

That HEV can trigger or unmask AlH is suggested by two reports, one from Japan and one from Spain [21, 28]. In the first report, a patient with acute HEV infection and positive ANA (IIF pattern not specified) was diagnosed with classical AIH five months after the acute episode, on the basis of chronic fatigue, negative HEV RNA in the blood, persistently elevated transaminase and IgG levels, positive ANA (1:640, pattern not reported) and typical histological findings [21]. A diagnosis of AlH following acute HEV infection is reported also in the Spanish series, in an ANA positive patient (pattern not described) with a prolonged hepatitis course despite clearance of HEV virus and liver histology compatible with AlH [28]. Though the patient did not fulfil the simplified IAIHG diagnostic criteria for AIH [33], there was an excellent response to steroids and azathioprine. Whether HEV played a direct role in the development of $\mathrm{AlH}$ or whether simply unveiled an underlying $\mathrm{AlH}$ in these two cases is unknown.

Of importance in the clinical setting, presence of ANA and/or anti-SMA during acute HEV infection has led to the erroneous diagnosis of $\mathrm{AlH}$ and inappropriate immunosuppressive treatment in a number of published case reports [17-20,34]. In none of these reports is there information on the immunofluorescence autoantibody appearance, which could have helped in discriminating between ANA and SMA patterns typically found in AlH and those present in a variety of other liver disorders, including viral hepatitis.

In our series, seven patients were positive for ANCA, including PANCA, CANCA and atypical pANCA (pANNA). Interestingly, none of these autoantibodies reacted with any of known molecular targets of ANCA as assessed by ELISA in small-vessel vasculitis, AlH, inflammatory bowel disease and sclerosing cholangitis [22]. CANCA or PANCA were detected during acute HEV infection also in three of 23 patients in the above mentioned Spanish series [28], where positivity for ANA, ANCA or AMA was reported in $30 \%$. It is 
unclear whether other autoantibodies were sought and what techniques were used, but it is of interest that one of the Spanish patients, like one of our patients, was positive for AMA. AMA in our case was atypical, not showing the specificity characteristic of AMA in PBC when tested immunochemically, and was not associated with biochemical cholestasis; it disappeared at follow-up 10 months after acute HEV infection, with persistently normal liver biochemistry values, suggesting that it may be induced by HEV infection without impacting the course of the disease. Transient positivity for AMA has been reported in patients presenting with acute liver failure [35].

In our series, no patient went on developing AlH over a short follow-up period (median clinical follow up 20 months), including the two patients who, in association with ANA, had a SMA pattern considered AIH-specific. One of them, a SMA-positive lady with VGT IIF pattern, was diagnosed with celiac disease at the same time as acute HEV-infection, and developed erythema nodosum and pulmonary sarcoidosis one year later. The other patient, also female, had SMA with VG IIF pattern, and had a past history of microscopic colitis treated with budesonide. Both patients, therefore, appear to have a predisposition to the development of autoimmune diseases and merit longer term follow up to monitor possible progression to autoimmune liver disease.

Extrahepatic autoimmunity is well documented in AlH patients, as $20 \%$ have concomitant autoimmune disorders, or will develop them during follow up, and up to $40 \%$ have a family history of autoimmune disease [7]. The association between AIH and celiac disease is also well described [36, 37]. It is conceivable that HEV infection might be one of multiple hits leading to $\mathrm{AlH}$, as postulated in the above mentioned case of $\mathrm{AlH}$ following $\mathrm{HCV}$ infection $[11,38]$. In this context it is of interest that in a series of 252 UK patients screened for autoantibodies, AlH-specific anti-SMA positivity presaged progression to AlH over a median follow up of 9 years in association with fluctuating transaminase levels, suggesting that our two patients should be followed up long-term [39].

HEV is associated with extrahepatic manifestations, including, among others, Guillain-Barré syndrome, neuralgic amyotrophy, thrombocytopenia, and glomerulonephritis, for which an immune-mediated mechanism has been suggested [40-45]. The observation that HEVtriggered immune-mediated phenomena are associated with less severe acute hepatitis [46] might explain the intriguing finding in our cohort that SMA positivity was associated with lower transaminase levels. As only one of our two patients with AlH-specific SMA had extrahepatic complications (neuralgic amyotrophy), it is not possible to speculate whether 
these are linked to HEV infection, but further investigations are warranted.

\section{Conclusions}

In conclusion, our study underscores two important facts. On the one hand it shows that non-specific autoantibodies associated to AlH are frequently present during acute HEV infection. Clinicians should be aware of this and always exclude acute HEV infection before diagnosing and treating $\mathrm{AlH}$, as immunosuppression can lead to chronic HEV disease [3]. On the other hand, it is conceivable that in predisposed subjects, HEV infection might trigger $\mathrm{AlH}$ : patients positive for $\mathrm{AlH}$-specific serology, should be carefully followed up long-term.

\section{Funding}

This work was supported by Fondazione Epatocentro Ticino and ABREOC Foundation of EOC (Grant 2016, Ripellino and Gobbi).

\section{Acknowledgement}

We are in debt to Emanuela Pasi, Gladys Martinetti and Paola Messina for their support in sample handling. We also kindly acknowledge Costanzo Limoni for the biostatistical analysis, and Darius Moradpour, Monserrat Fraga, Roland Sahli and Vincent Aubert for their collaboration to the NEUROCAVE study.

\section{References}

1. Dalton HR, Kamar N, Izopet J (2014) Hepatitis E in developed countries: current status and future perspectives. Future Microbiol 9:1361-1372 . doi: 10.2217/fmb.14.89

2. Dalton HR, Hunter JG, Bendall R (2013) Autochthonous hepatitis E in developed countries and HEV/HIV coinfection. Semin Liver Dis 33:50-61 . doi: 10.1055/s-0033-1338114 
3. Lhomme S, Bardiaux L, Abravanel F, et al (2017) Hepatitis E Virus Infection in Solid Organ Transplant Recipients, France. Emerg Infect Dis 23:353-356 . doi: 10.3201/eid2302.161094

4. Hartl J, Otto B, Madden RG, et al (2016) Hepatitis E Seroprevalence in Europe: A MetaAnalysis. Viruses 8: . doi: 10.3390/v8080211

5. Kaufmann A, Kenfak-Foguena A, André C, et al (2011) Hepatitis E virus seroprevalence among blood donors in southwest Switzerland. PloS One 6:e21150 . doi: 10.1371/journal.pone.0021150

6. Schnegg A, Bürgisser P, André C, et al (2013) An analysis of the benefit of using HEV genotype 3 antigens in detecting anti-HEV IgG in a European population. PloS One 8:e62980 . doi: 10.1371/journal.pone.0062980

7. Liberal R, Krawitt EL, Vierling JM, et al (2016) Cutting edge issues in autoimmune hepatitis. J Autoimmun. doi: 10.1016/j.jaut.2016.07.005

8. Vergani D, Mackay IR, Mieli-Vergani G (2014) Chapter 61 - Hepatitis. In: The Autoimmune Diseases (Fifth Edition). Academic Press, Boston, pp 889-907

9. Longhi MS, Ma Y, Mieli-Vergani G, Vergani D (2010) Aetiopathogenesis of autoimmune hepatitis. J Autoimmun 34:7-14 . doi: 10.1016/j.jaut.2009.08.010

10. Cassani F, Cataleta M, Valentini $P$, et al (1997) Serum autoantibodies in chronic hepatitis C: comparison with autoimmune hepatitis and impact on the disease profile. Hepatol Baltim Md 26:561-566 . doi: 10.1002/hep.510260305

11. Bogdanos DP, Choudhuri K, Vergani D (2001) Molecular mimicry and autoimmune liver disease: virtuous intentions, malign consequences. Liver 21:225-232

12. Bogdanos DP, Ma Y, Hadzic N, et al (2004) P0295 VIRUS-SELF CROSSREACTIVITY INDUCING DE NOVO AUTOIMMUNE HEPATITIS EIGHT-YEARS AFTER LIVER TRANSPLANTATION. J Pediatr Gastroenterol Nutr 39:S169

13. Pischke S, Gisa A, Suneetha PV, et al (2014) Increased HEV seroprevalence in patients with autoimmune hepatitis. PloS One 9:e85330 . doi: 10.1371/journal.pone.0085330

14. Taubert R, Diestelhorst J, Junge N, et al (2017) Potential viral triggers for pediatric and adult autoimmune hepatitis. J Hepatol 66:S109 . doi: 10.1016/S0168-8278(17)30477-4

15. van Gerven NMF, van der Eijk AA, Pas SD, et al (2016) Seroprevalence of Hepatitis E Virus in Autoimmune Hepatitis Patients in the Netherlands. J Gastrointest Liver Dis JGLD 25:9-13

16. Hogema BM, Molier M, Sjerps $M$, et al (2016) Incidence and duration of hepatitis $E$ virus infection in Dutch blood donors. Transfusion (Paris) 56:722-728 . doi: 10.1111/trf.13402

17. Nagasaki F, Ueno $Y$, Kanno N, et al (2005) A case of acute hepatitis with positive autoantibodies who actually had hepatitis E virus infection. Hepatol Res Off J Jpn Soc Hepatol 32:134-137 . doi: 10.1016/j.hepres.2005.03.017 
18. Patel I, Companioni RC, Bansal R, et al (2016) Acute hepatitis E presenting with clinical feature of autoimmune hepatitis. J Community Hosp Intern Med Perspect 6: . doi:

10.3402/jchimp.v6.33342

19. Vieira CL, Baldaia C, Fatela N, et al (2013) Case of acute hepatitis E with concomitant signs of autoimmunity. World J Hepatol 5:152-155 . doi: 10.4254/wjh.v5.i3.152

20. Haïm-Boukobza S, Ferey M-P, Vétillard A-L, et al (2012) Transfusion-transmitted hepatitis $E$ in a misleading context of autoimmunity and drug-induced toxicity. J Hepatol 57:1374-1378 . doi: 10.1016/j.jhep.2012.08.001

21. Kanda T, Yasui S, Nakamura M, et al (2015) Recent Trend of Hepatitis E Virus Infection in Chiba Area, Japan: 3 of 5 Cases with Rheumatoid Arthritis. Case Rep Gastroenterol 9:317-326 . doi: $10.1159 / 000441387$

22. Terziroli Beretta-Piccoli B, Mieli-Vergani G, Vergani D (2017) Serology in autoimmune hepatitis: A clinical-practice approach. Eur J Intern Med. doi: 10.1016/j.ejim.2017.10.006

23. Vergani D, Alvarez F, Bianchi FB, et al (2004) Liver autoimmune serology: a consensus statement from the committee for autoimmune serology of the International Autoimmune Hepatitis Group. J Hepatol 41:677-683 . doi: 10.1016/j.jhep.2004.08.002

24. Oberhuber G (2000) Histopathology of celiac disease. Biomed Pharmacother Biomedecine Pharmacother 54:368-372 . doi: 10.1016/S0753-3322(01)80003-2

25. Farrow L, Holborow EJ, Johnson GD, et al (1970) Autoantibodies and the hepatitis-associated antigen in acute infective hepatitis. Br Med J 2:693-695

26. Abdel-Ghaffar TY, Sira MM, Sira AM, et al (2015) Serological markers of autoimmunity in children with hepatitis A: relation to acute and fulminant presentation. Eur J Gastroenterol Hepatol 27:1161-1169 . doi: 10.1097/MEG.0000000000000413

27. Moon HW, Noh JK, Hur M, et al (2009) High prevalence of autoantibodies in hepatitis $A$ infection: the impact on laboratory profiles. J Clin Pathol 62:786-788 . doi: 10.1136/jcp.2009.064410

28. Monteserín Ron L, Jiménez Palacios M, Linares Torres P, et al (2017) Autochthonous acute hepatitis $\mathrm{E}$ : an increasingly frequent diagnosis. Clinical-epidemiological analysis of our experience. Rev Espanola Enfermedades Dig Organo Of Soc Espanola Patol Dig 109:344-349. doi: $10.17235 /$ reed.2017.4258/2016

29. Gregorio GV, Jones H, Choudhuri K, et al (1996) Autoantibody prevalence in chronic hepatitis B virus infection: effect in interferon alfa. Hepatol Baltim Md 24:520-523 . doi: 10.1002/hep.510240309

30. Muratori L, Cataleta M, Muratori P, et al (1998) Liver/kidney microsomal antibody type 1 and liver cytosol antibody type 1 concentrations in type 2 autoimmune hepatitis. Gut 42:721-726

31. Ozaras R, Tahan V, Tabak F (2016) More on autoimmune hepatitis and acute hepatitis A. Eur J Gastroenterol Hepatol 28:360 . doi: 10.1097/MEG.0000000000000521 
32. Vento $S$, Cainelli $F(2004)$ Is there a role for viruses in triggering autoimmune hepatitis? Autoimmun Rev 3:61-69 . doi: 10.1016/S1568-9972(03)00053-3

33. Hennes EM, Zeniya M, Czaja AJ, et al (2008) Simplified criteria for the diagnosis of autoimmune hepatitis. Hepatol Baltim Md 48:169-176 . doi: 10.1002/hep.22322

34. Inagaki Y, Oshiro Y, Hasegawa N, et al (2015) Clinical features of hepatitis E virus infection in Ibaraki, Japan: autochthonous hepatitis $\mathrm{E}$ and acute-on-chronic liver failure. Tohoku J Exp Med 235:275-282 . doi: 10.1620/tjem.235.275

35. Leung PSC, Rossaro L, Davis PA, et al (2007) Antimitochondrial antibodies in acute liver failure: implications for primary biliary cirrhosis. Hepatol Baltim Md 46:1436-1442 . doi: 10.1002/hep. 21828

36. van Gerven NM, Bakker SF, de Boer YS, et al (2014) Seroprevalence of celiac disease in patients with autoimmune hepatitis. Eur J Gastroenterol Hepatol 26:1104-1107 . doi: 10.1097/MEG.0000000000000172

37. Muratori P, Fabbri A, Lalanne C, et al (2015) Autoimmune liver disease and concomitant extrahepatic autoimmune disease. Eur J Gastroenterol Hepatol 27:1175-1179 . doi: 10.1097/MEG.0000000000000424

38. Bogdanos DP, Mieli-Vergani G, Vergani D (2009) Autoantibodies and their antigens in autoimmune hepatitis. Semin Liver Dis 29:241-253 . doi: 10.1055/s-0029-1233533

39. Healey R, Corless L, Gordins P, Holding S (2016) Do anti-smooth muscle antibodies predict development of autoimmune hepatitis in patients with normal liver function? - A retrospective cohort review. Autoimmun Rev 15:668-672 . doi: 10.1016/j.autrev.2016.03.001

40. van den Berg B, van der Eijk AA, Pas SD, et al (2014) Guillain-Barré syndrome associated with preceding hepatitis $E$ virus infection. Neurology 82:491-497 . doi: 10.1212/WNL.0000000000000111

41. van Eijk JJJ, Madden RG, van der Eijk AA, et al (2014) Neuralgic amyotrophy and hepatitis E virus infection. Neurology 82:498-503 . doi: 10.1212/WNL.0000000000000112

42. Singh NK, Gangappa M (2007) Acute immune thrombocytopenia associated with hepatitis $E$ in an adult. Am J Hematol 82:942-943 . doi: 10.1002/ajh.20960

43. Guinault D, Ribes D, Delas A, et al (2016) Hepatitis E Virus-Induced Cryoglobulinemic Glomerulonephritis in a Nonimmunocompromised Person. Am J Kidney Dis Off J Natl Kidney Found 67:660-663 . doi: 10.1053/j.ajkd.2015.10.022

44. Kamar N, Marion O, Abravanel F, et al (2016) Extrahepatic manifestations of hepatitis E virus. Liver Int Off J Int Assoc Study Liver 36:467-472 . doi: 10.1111/liv.13037

45. Woolson KL, Forbes A, Vine L, et al (2014) Extra-hepatic manifestations of autochthonous hepatitis E infection. Aliment Pharmacol Ther 40:1282-1291 . doi: 10.1111/apt.12986 
46. van Eijk JJJ, Dalton HR, Ripellino P, et al (2017) Clinical phenotype and outcome of hepatitis E virus-associated neuralgic amyotrophy. Neurology 89:909-917 . doi:

10.1212/WNL.0000000000004297 
_Table 1. Clinical features of the study population and results of liver autoimmune serology testing.

\begin{tabular}{|c|c|c|c|c|c|c|c|c|c|}
\hline Patient & Gender & Age & $\begin{array}{l}\text { ALT at HEV } \\
\text { diagnosis } \\
(U I / I), U L N \\
50 \mathrm{U} / \mathrm{I}\end{array}$ & ANA & SMA & ANCA & $\begin{array}{l}\text { Follow-up } \\
\text { autoimmune } \\
\text { serology }\end{array}$ & $\begin{array}{l}\text { Follow-up ALT } \\
\text { levels (U/I), } \\
\text { ULN } 50 \mathrm{U} / \mathrm{I}\end{array}$ & Concomitant diseases \\
\hline 1 & $M$ & 44 & 50 & - & - & - & & & \\
\hline 2 & $\mathrm{~F}$ & 40 & 106 & - & - & - & & & \\
\hline 3 & $M$ & 50 & 29 & 1:80 spk & - & - & & & \\
\hline 4 & $M$ & 83 & 21 & - & $1: 80 \mathrm{~V}$ & - & & & $\begin{array}{l}\text { History of chronic inflammatory } \\
\text { demyelinating polyneuropathy }\end{array}$ \\
\hline 5 & $\mathrm{~F}$ & 44 & 24 & - & - & - & & & \\
\hline 6 & $\mathrm{M}$ & 52 & 639 & - & - & - & & & $\begin{array}{l}\text { Alcohol abuse, diabetes } \\
\text { following pancreas surgery }\end{array}$ \\
\hline 7 & $\mathrm{M}$ & 24 & 8 & $\begin{array}{l}\text { 1:80 } \\
\text { spk/hom }\end{array}$ & - & - & & & \\
\hline 8 & $\mathrm{M}$ & 76 & 1445 & 1:160 spk & & & & & Type II diabetes \\
\hline 9 & $\mathrm{M}$ & 57 & 26 & - & - & - & & 34 & Systemic sarcoidosis \\
\hline 10 & $M$ & 38 & 22 & $\begin{array}{l}\text { 1:80 } \\
\text { spk/hom }\end{array}$ & $1: 80 \mathrm{~V}$ & - & & & \\
\hline 11 & $\mathrm{M}$ & 63 & 348 & - & - & - & & & Kidney transplant recipient \\
\hline 12 & $M$ & 44 & 5457 & - & - & - & & & \\
\hline 13 & $M$ & 29 & 914 & - & - & - & & & \\
\hline 14 & $\mathrm{~F}$ & 42 & 88 & - & $1: 160 \mathrm{~V}$ & - & & & \\
\hline 15 & $M$ & 48 & 558 & - & - & - & & & \\
\hline 16 & $M$ & 56 & 100 & $\begin{array}{l}1: 80 \\
\text { spk/misp }\end{array}$ & - & - & & & \\
\hline 17 & $\mathrm{M}$ & 65 & 85 & - & - & - & & & \\
\hline 18 & $\mathrm{~F}$ & 70 & 1791 & - & - & - & & & Type II diabetes \\
\hline
\end{tabular}




\begin{tabular}{|c|c|c|c|c|c|c|c|c|c|}
\hline 19 & $\mathrm{~F}$ & 45 & 25 & $1: 320 \mathrm{spk}$ & - & - & & & Hashimoto thyroiditis \\
\hline 20 & $\mathrm{~F}$ & 68 & 80 & - & - & - & & & Giant cell arteritis, alcohol abuse \\
\hline 21 & $\mathrm{M}$ & 46 & 210 & - & $1: 80 \mathrm{~V}$ & - & & & Type I diabetes, alcohol abuse \\
\hline 22 & $\mathrm{M}$ & 78 & 3519 & - & - & - & & & Type II diabetes \\
\hline 23 & $\mathrm{~F}$ & 54 & 521 & 1:160 spk & $1: 160 \mathrm{~V}$ & - & $\begin{array}{l}\text { ANA neg, } \\
\text { SMA 1:40v } \\
\text { after } 11 \\
\text { months }\end{array}$ & 23 & $\begin{array}{l}\text { Kidney and pancreas transplant } \\
\text { recipient, type I diabetes. } \\
\text { Chronic HEV infection treated } \\
\text { with RBV, virus cleared after } 12 \\
\text { months. }\end{array}$ \\
\hline 24 & $\mathrm{~F}$ & 40 & n.a. & - & $1: 80 \mathrm{~V}$ & - & & & \\
\hline 25 & $\mathrm{~F}$ & 51 & 251 & $\begin{array}{l}\text { 1:640 } \\
\text { spk/misp }\end{array}$ & $\begin{array}{l}1: 320 \\
\text { VGT }\end{array}$ & - & $\begin{array}{l}\text { ANA } 1: 320 \\
\text { spk, SMA } \\
1: 160 v \text { after } \\
12 \text { months }\end{array}$ & $\begin{array}{l}16 \text { ( } 3 \text { months } \\
\text { after acute } \\
\text { HEV infection) }\end{array}$ & $\begin{array}{l}\text { Celiac disease diagnosed at the } \\
\text { same time as HEV. Erythema } \\
\text { nodosum and sarcoidosis } 1 \text { year } \\
\text { after HEV infection. }\end{array}$ \\
\hline 26 & $\mathrm{~F}$ & 53 & 390 & - & - & - & & & \\
\hline 27 & $\mathrm{M}$ & 49 & 593 & - & - & - & & & \\
\hline 28 & $\mathrm{M}$ & 74 & 1548 & - & - & - & & & Type II diabetes \\
\hline 29 & $\mathrm{~F}$ & 77 & 92 & 1:80 hom & $\begin{array}{l}1: 320 \\
\text { VG }\end{array}$ & - & & $\begin{array}{l}22 \text { (one month } \\
\text { after acute } \\
\text { HEV infection) }\end{array}$ & $\begin{array}{l}\text { Microscopic colitis many years } \\
\text { before HEV infection }\end{array}$ \\
\hline 30 & $\mathrm{M}$ & 62 & 53 & - & - & - & & & $\begin{array}{l}\text { Alcoholic liver cirrhosis, previous } \\
\text { HCV cured } 19 \text { months before } \\
\text { HEV infection. }\end{array}$ \\
\hline $31^{*}$ & $\mathrm{M}$ & 46 & 1552 & $\begin{array}{l}\text { 1:160 } \\
\text { spk }\end{array}$ & - & - & $\begin{array}{l}\text { ANA and } \\
\text { AMA neg } \\
\text { after } 10 \\
\text { months }\end{array}$ & 5 & \\
\hline 32 & $\mathrm{M}$ & 61 & 248 & 1:160 nuc & - & - & $\begin{array}{l}\text { ANA neg } \\
\text { after } 10 \\
\text { months }\end{array}$ & 19 & \\
\hline
\end{tabular}




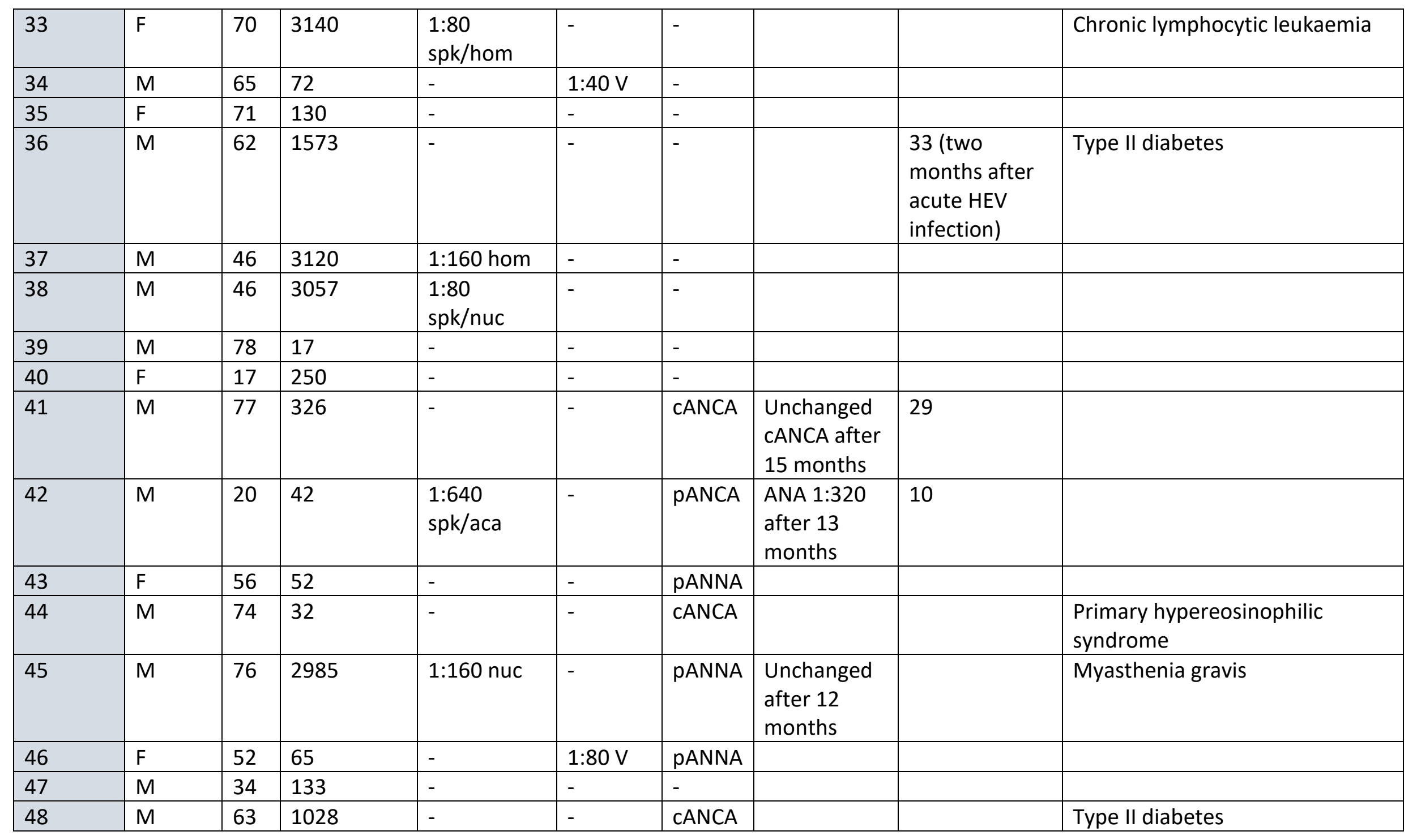

None of the patients tested positive for antibodies to liver kidney microsomes, liver cytosol type 1 or soluble liver antigen 
*Transiently positive for atypical anti-mitochondrial antibody (positive immunofluorescence, but negative immunoblot)

ALT, alanine amino-transferase; ANA, anti-nuclear antibodies; SMA, smooth-muscle antibodies; pANCA, perinuclear anti-neutrophilic cytoplasmic antibody; cANCA, cytoplasmic anti-neutrophilic cytoplasmic antibodies; pANNA, peripheral anti-nuclear neutrophilic antibodies; spk, speckled; misp, mitotic spindle; v, vessel; t, tubular; g, glomerular; hom, homogeneous; nuc, nucleolar; aca, anti-centromere; ULN, upper limit of normal. 